\title{
Gas, Water and Solid Waste Treatment Technology
}

\author{
Wenxiang Zhang ${ }^{1}$, Zhien Zhang ${ }^{2, *(D)}$ and Avelino Núñez-Delgado ${ }^{3}$ (D) \\ 1 Department of Civil and Environmental Engineering, Faculty of Science and Technology, \\ University of Macau, Macau 999078, China; wxzhang@um.edu.mo \\ 2 Department of Chemical and Biomedical Engineering, West Virginia University, \\ Morgantown, WV 26506, USA \\ 3 Department of Soil Science and Agricultural Chemistry, Engineering Polytechnic School, \\ University of Santiago de Compostela, 27002 Lugo, Spain; avelino.nunez@usc.es \\ * Correspondence: zhien.zhang@mail.wvu.edu
}

Citation: Zhang, W.; Zhang, Z.; Núñez-Delgado, A. Gas, Water and Solid Waste Treatment Technology. Processes 2021, 9, 1397. https:// doi.org/10.3390/pr9081397

Received: 11 August 2021

Accepted: 11 August 2021

Published: 12 August 2021

Publisher's Note: MDPI stays neutral with regard to jurisdictional claims in published maps and institutional affiliations.

Copyright: (C) 2021 by the authors Licensee MDPI, Basel, Switzerland. This article is an open access article distributed under the terms and conditions of the Creative Commons Attribution (CC BY) license (https:// creativecommons.org/licenses/by/ $4.0 /)$.
The increasing trends in gas pollution, water pollution, and solid waste pollution have an adverse impact on human health and ecological habitats. Various technologies have been deployed to treat different pollutants [1,2]. Nevertheless, many of these technologies render poor performance or are yet to be economically feasible for commercial deployment. Therefore, devising efficient treatment processes and associated technologies has become paramount in the past few years.

In the current Special Issue in Processes, 34 review and research papers on the applications of novel techniques, processes and theories in gas, water and solid waste treatment have been presented. The Special Issue is available online at: https://www.mdpi.com/ journal/processes/special_issues/waste_treatment. A concise summary of the presented works in this Special Issue is outlined here.

In the work of Cela-Dablanca et al. [3], the competitive adsorption/desorption of tetracycline (TC) and sulfadiazine (SDZ) onto pine bark, oak ash and mussel shell was investigated. The study was carried out using batch-type experiments in binary systems (with both antibiotics present simultaneously), adding five equal concentrations of the antibiotics (between 1 and $50 \mu \mathrm{mol} / \mathrm{L}$ ). The adsorption percentages were higher for TC (close to $100 \%$ onto pine bark and oak ash, and between $40 \%$ and $85 \%$ onto mussel shell) than for SDZ (75-100\% onto pine bark, and generally less than $10 \%$ on oak ash and mussel shell). Pine bark performed as the best adsorbent since TC adsorption remained close to $100 \%$ throughout the entire concentration range tested, while it was between 75 and 100\% for SDZ. Desorption was always higher for SDZ than for TC. The results of this study could be useful to design practices to protected environmental compartments receiving discharges that simultaneously contain the two antibiotics evaluated here, and therefore could be relevant in terms of protection of the environment and public health.

Baena-Moreno et al. [4] studied the novel method for energy recovery from molten synthetic slags. In the work, the potential energy that could be recovered from the production of synthetic slag is estimated by means of an integrated experimental-theoretical study. The energy to be recovered comes from the cooling-solidification stage of the synthetic slag manufacturing. Traditionally, the solidification stage has been carried out through quick cooling with water, which does not allow the energy recovery. Moreover, a novel cooling method based on metal spheres is presented, which allows the energy recovery from the molten slags. Two points present novelty in this work: (1) the method for measuring the metal spheres temperature; (2) and the estimation of the energy that could be recovered from these systems in slag manufacturing. The results forecasted that the temperature achieved by the metal spheres was in the range of $295-410{ }^{\circ} \mathrm{C}$ in the center and $302-482{ }^{\circ} \mathrm{C}$ on the surface. Furthermore, we estimated that $325-550 \mathrm{~kJ} / \mathrm{kg}$ of molten material could be recovered, of which $15 \%$ of the energy consumption is in the synthetic slag manufacturing process. Overall, the results obtained confirmed the potential of our proposal for energy recovery from the cooling-solidification stage of synthetic slag manufacturing. 
In the study of Do et al. [5], ZnO nanoparticles were fabricated by using the hydrothermal method for adsorption of phosphate from wastewater. The obtained $\mathrm{ZnO}$ nanorods were characterized by powder X-ray diffraction spectroscopy, scanning electron microscopy, specific surface area and energy-dispersive $\mathrm{X}$-ray spectroscopy. The $\mathrm{ZnO}$ materials were applied for adsorption of phosphate from water using batch experiments. The effects of $\mathrm{pH}(4-10)$, adsorption time (30-240 $\mathrm{min})$, the amount of adsorbent $(0.1-0.7 \mathrm{~g} / \mathrm{L})$ and initial concentration of phosphate (147.637-466.209 mg/L) on the adsorption efficiency were investigated. The optimal condition was found at $\mathrm{pH}=5$ and at an adsorption time of $150 \mathrm{~min}$. The adsorption was fitted well with the Langmuir isotherm and the maximum adsorption capacity was calculated to be $769.23 \mathrm{mg} / \mathrm{g}$. These results show that $\mathrm{ZnO}$ nanomaterial would be highly promising for adsorbing phosphate from water. The adsorption of phosphate on $\mathrm{ZnO}$ nanomaterials follows the isothermal adsorption model of Langmuir, Tempkin and Freundlich with single-layer adsorption. There is a weak interaction between the adsorbent and the adsorbate. Phosphate adsorption of the $\mathrm{ZnO}$ nanomaterials follows Lagergren's apparent second-order kinetic model and was spontaneous and exothermic.

Liu et al. [6] reported that two kinds of tri-high coals were selected to determine the influences of ash-existing environments and coal structures on $\mathrm{CO}_{2}$ gasification characteristics. The TGA results showed that the gasification of ash-free coal (AFC) chars was more efficient than that of corresponding raw coal (RC) chars. To uncover the reasons, the structures of RCs and AFCs, and their char samples prepared at elevated temperatures were investigated with SEM, BET, XRD, Raman and FTIR. The BET, SEM and XRD results showed that the ash/mineral matter is associated with coal, carbon forms the main structural framework and mineral matters are found embedded in the coal structure in the low-rank tri-high coal. The Raman and FTIR results show that the ash can hinder volatile matters from exposing to the coal particles. Those results indicate that the surface of AFC chars has more free active carbon sites than raw coal chars, which are favorable for mass transfer between $\mathrm{C}$ and $\mathrm{CO}_{2}$, thereby improving reactivity of the AFC chars. However, the gasification reactivity was dominated by pore structure at elevated gasification temperatures, even though the microcrystalline structure, functional group structure, and increase in the disorder carbon were improved by acid pickling.

Siddiqi et al. [7] argued that the ecosystem of Earth, the habitat of 7.53 billion people and more than 8.7 million species, is being imbalanced by anthropogenic activities. The ever-increasing human population and race of industrialisation is an exacerbated threat to the ecosystem. At present, the global average waste generation per person is articulated as $494 \mathrm{~kg}$ /year, an enormous amount of household waste (HSW) that ultimately hits $3.71 \times 10^{12} \mathrm{~kg}$ of waste in one year. The ultimate destination of HSW is a burning issue because open dumping and burning as the main waste treatment and final disposal systems create catastrophic environmental limitations. This paper strives to contribute to this issue of HSW management that matters to everyone, specifically developing nations. The HSW management system of the world's 12th largest city and 24th most polluted city, Karachi, was studied with the aim of generating possible economic gains by recycling HSWs. In this regard, the authors surveyed dumping sites for sample collection. The sample was segregated physically to determine the content type (organic, metals, and many others). Afterward, chemical analysis with atomic absorption spectrophotometry (AAS) of debris and soil from a landfill site was performed. HSW is classified and quantified into major classes of household materials. The concentrations of e-waste [Cu], industrial development indicator [Fe], and the main component of lead-acid storage batteries $[\mathrm{Pb}]$ are quantified as $199.5,428.5$, and $108.5 \mathrm{ppm}$, respectively. The annual generation of the aforementioned metals as waste recovery is articulated as $1.2 \times 10^{6}, 2.6 \times 10^{6}$ and $6.5 \times 10^{5} \mathrm{~kg}$, respectively. Significantly, this study concluded that a result-based metal recovery worth 6.1 million USD is discarded every year in HSW management practices.

Ji et al. [8] reported that conversion of algal biomass into energy products via gasification has attracted increasing research interest. A basic understanding of the gasification kinetics of algal biomass is of fundamental importance. The distributed activation energy 
model (DAEM), which provides the information of energy barrier distribution during the gasification process, is a promising tool to study the kinetic process of algae gasification. In this study, the DAEM model was used to investigate Chlorella vulgaris and Spirulina gasification. The activation energy of Chlorella vulgaris gasification was in the range from 370 to $650 \mathrm{~kJ} / \mathrm{mol}$. The range of activation energy for Spirulina gasification was a bit wider, spanning from 330 to $670 \mathrm{~kJ} / \mathrm{mol}$. The distribution of activation energy for both Chlorella vulgaris and Spirulina showed that $500 \mathrm{~kJ} / \mathrm{mol}$ had the most components, and these components were gasified at around $300{ }^{\circ} \mathrm{C}$. The DAEM algorithm was validated by the conversion and conversion rate from experimental measurement, demonstrating that DAEM is accurate to describe the kinetics of algal biomass gasification.

Peceño et al. [9] studied the waste recycling in waste management. The concrete industry allows the use of large quantities of waste as a substitute for a conventional raw material without sacrificing the technical properties of the product. From a circular economy point of view, this is an excellent opportunity for waste recycling. Nevertheless, in some cases, the recycling process can be undesirable because it does not involve a net saving in resource consumption or other environmental impacts when compared to the conventional production process. In this study, the environmental performance of conventional absorption porous barriers, composed of $86 \mathrm{wt} \%$ of natural aggregates and $14 \mathrm{wt} \%$ cement, was compared with barriers composed of $80 \mathrm{wt} \%$ seashell waste and $20 \mathrm{wt} \%$ cement through an attributional cradle-to-grave life cycle assessment. The results show that, for the 11 environmental impact categories considered, the substitution of the natural aggregates with seashell waste involves higher environmental impacts, between $32 \%$ and $267 \%$. These results are justified by the high contribution to these impacts of the seashell waste pre-treatment and the higher cement consumption. Therefore, the recycling of seashells in noise barrier manufacturing is not justified from an environmental standpoint with the current conditions. In this sense, it could be concluded that life cycle assessments should be carried out simultaneously with the technical development of the recycling process to ensure a sustainable solution.

In the study of Nkosi et al. [10], some of today's modern life challenges include addressing the increased waste generation and energy deficiencies. Waste tyres have been identified as one of the key environmental concerns due to their non-biodegradable nature and bulk storage space demand. Pyrolysis is a thermochemical process with the potential to address the growing waste tyre problem, energy deficits, and material recovery by converting waste tyres to pyrolysis oil that can be used as a fuel. This study seeks to critically evaluate the feasibility of constructing and operating a waste tyre processing facility and then subsequently marketing and selling the pyrolysis secondary end products by developing a financial business model. The model encompasses costing, procurement, installation, commissioning, and operating a batch pyrolysis plant in Gauteng, South Africa. To achieve the study objectives, an order of magnitude costing method was used for model construction. The results showed the feasibility and sustainability of operating a 3.5 tonne per day batch waste tyre pyrolysis plant in Gauteng Province, South Africa, with a 15-year life span and a projected payback period of approximately 5 years. It was concluded that for the pyrolysis plant to be successful, further treatment steps are required to improve the process economics; also, a stable and sustainable product market should exist and be regulated in South Africa.

Shaaban et al. [11] analyzed the impact of liming materials in terms of exploring the effect of soil $\mathrm{pH}$ change on $\mathrm{N}_{2} \mathrm{O}$ emissions. In the study, a soil with $\mathrm{pH} 5.35$ was amended with liming materials $\left(\mathrm{CaMg}\left(\mathrm{CO}_{3}\right)_{2}, \mathrm{CaCO}_{3}, \mathrm{Ca}(\mathrm{OH})_{2}\right.$ and $\left.\mathrm{CaO}\right)$ to investigate their effects on $\mathrm{N}_{2} \mathrm{O}$ emissions. The results indicate that the application of liming materials reduced the magnitudes of $\mathrm{N}_{2} \mathrm{O}$ emissions. The maximum reduction of soil $\mathrm{N}_{2} \mathrm{O}$ emissions took place for $\mathrm{Ca}(\mathrm{OH})_{2}$ treatment when compared to the other liming materials, and was related to increasing soil $\mathrm{pH}$. Mineral $\mathrm{N}$, dissolved organic $\mathrm{C}$, and microbial biomass $\mathrm{C}$ were also influenced by liming materials, but the trend was inconsistent to the soil $\mathrm{pH}$ change. The results suggest that $\mathrm{N}_{2} \mathrm{O}$ emission mitigation is more dependent on soil $\mathrm{pH}$ than $\mathrm{C}$ and 
$\mathrm{N}$ dynamics when comparing the different liming materials. Moreover, ameliorating soil acidity is a promising option to mitigate $\mathrm{N}_{2} \mathrm{O}$ emissions from acidic soils.

Charis et al. [12] studied the bioenergy production potential from biomasses. The study characterized pine sawdust samples from Zimbabwe and acacia tortilis samples from Botswana using conventional and spectrometry techniques. The ultimate analysis results for pine were $45.76 \%$ carbon $(\mathrm{C}), 5.54 \%$ hydrogen $(\mathrm{H}), 0.039 \%$ nitrogen $(\mathrm{N}), 0 \%$ sulphur (S) and $48.66 \%$ oxygen (O) and, for acacia, were $41.47 \% \mathrm{C}, 5.15 \% \mathrm{H}, 1.23 \% \mathrm{~N}, 0 \% \mathrm{~S}$ and $52.15 \%$ O. Due to the low N and $\mathrm{S}$ in the biomasses, they promise to provide cleaner energy than fossil-based sources. Proximate analysis results, on a dry basis, for acacia were $3.90 \%$ ash, $15.59 \%$ fixed carbon and $76.51 \%$ volatiles matter and $0.83 \%, 20 \%$ and $79.16 \%$, respectively, for pine. A calorific value of $17.57 \mathrm{MJ} / \mathrm{kg}$ was obtained for pine, compared with $17.27 \mathrm{MJ} / \mathrm{kg}$ for acacia, suggesting they are good thermochemical feedstocks. Acacia's bulk energy density is five times that of pine, making it excellent for compressed wood applications. Although the ash content in acacia was much higher than in pine, it fell below the fouling and slagging limit of $6 \%$. In pyrolysis, however, high ash contents lead to reduced yields or the quality of bio-oil through catalytic reactions. Fourier transform infrared spectrometry indicated the presence of multiple functional groups, as expected for a biomass and its derivatives.

In the study of Magzoub et al. [13], electric arc furnace dust has been evaluated as a potential, low-cost additive to increase the viscosity and weight of drilling muds. Currently, the cost of drilling operations typically accounts for $50 \%$ to $80 \%$ of the exploration costs and about $30 \%$ to $80 \%$ of the subsequent field development costs. Utilisation of steelmaking waste in drilling fluids formulations is aimed to produce new and optimized water-based drilling formulations, which is expected to reduce the amount of bentonite and other viscosifier additives used in the drilling formulations. The results showed that in a typical water-based drilling fluid of $8.6 \mathrm{ppg}\left(1030.51 \mathrm{~kg} / \mathrm{m}^{3}\right)$, the amount of standard drilling grade bentonite could be reduced by $30 \mathrm{wt} \%$ with the addition of the proposed new additive to complete the required mud weight. The mixture proved to be stable with no phase separation.

In the work of Alberdi et al. [14], the problem of municipal waste collection is modeled using a simple but efficient solution that is especially easy to maintain. Real data have been used, and it has been solved using a genetic algorithm. Computations have been undertaken in two different ways: using a complete random initial population, and including a seed in this initial population. In order to guarantee that the solution is efficient, the performance of the genetic algorithm has been compared with another well-performing algorithm, the variable neighborhood search. Three problems of different sizes have been solved and, in all cases, a significant improvement has been obtained. A total reduction of $40 \%$ of itineraries is attained with the subsequent reduction of emissions and costs.

Huang et al. [15] investigated that the ultrathin $\mathrm{MoS}_{2}$ nanosheets, a typical twodimensional material. In the work, a hybrid strategy with combination of quenching process and liquid-based exfoliation was employed to fabricate the ultrathin $\mathrm{MoS}_{2}$ nanosheets $\left(\mathrm{MoS}_{2} \mathrm{NS}\right)$. The obtained $\mathrm{MoS}_{2}$ NS still maintained hexagonal phase and exhibited evident thin layer-structure (1-2 layers) with inconspicuous wrinkles. Moreover, the $\mathrm{MoS}_{2} \mathrm{NS}$ dispersion showed excellent stability (over 60 days) and high concentration $(0.65 \pm 0.04 \mathrm{mg} / \mathrm{mL})$. The $\mathrm{MoS}_{2}$ NS dispersion also displayed evident optical properties, with two characteristic peaks at 615 and $670 \mathrm{~nm}$, and could be quantitatively analyzed with the absorbance at $615 \mathrm{~nm}$ in the range of $0.01-0.5 \mathrm{mg} / \mathrm{mL}$. The adsorption experiments showed that the as-prepared $\mathrm{MoS}_{2} \mathrm{NS}$ also exhibited remarkable adsorption performance on the dyes ( 344.8 and $123.5 \mathrm{mg} / \mathrm{g}$ of $q_{m}$ for methylene blue and methyl orange, respectively) and heavy metals $\left(185.2,169.5\right.$, and $70.4 \mathrm{mg} / \mathrm{g}$ of $q_{m}$ for $\mathrm{Cd}^{2+}, \mathrm{Cu}^{2+}$, and $\left.\mathrm{Ag}^{+}\right)$. During the adsorption, the main adsorption mechanisms involved the synergism of physical hole-filling effects and electrostatic interactions. This work provided an effective way for the large-scale fabrication of the two-dimensional nanosheets of transition metal dichalcogenides by liquid exfoliation. 
Abdelatif et al. [16] reported that large amounts of carbonated mud waste (CMW) require disposal during sugar manufacturing after the carbonation process. The lightweight of CMW enables its utilisation as a partial replacement for the cement to reduce costs and $\mathrm{CO}_{2}$ emissions. Here, various levels of CMW, namely, 0, 5, 10, 15, 20, and $25 \mathrm{wt} \%$ were applied to produce composite cement samples with ordinary Portland cement (OPC) as a regular mix design series. Pure calcium oxide $(\mathrm{CaO})$ nanoparticles were obtained after the calcination of CMW. The techniques of X-ray fluorescence spectrometers, Transmission electron microscope, selected area diffraction, scanning electron microscope, energy-dispersive $\mathrm{X}$-ray, and dynamic light scattering were used to characterize the obtained $\mathrm{CaO}$ nanoparticles. According to the compressive strength and bulk density results, $15 \mathrm{wt} \% \mathrm{CMW}$ was optimal for the mix design. The specific surface area increased from 27.8 to $134.8 \mathrm{~m}^{2} / \mathrm{g}$ when the CMW was calcined to $600^{\circ} \mathrm{C}$. The compressive strength of the sample containing $15 \%$ CMW was lower than the values of the other pastes containing $5 \%$ and $10 \% \mathrm{CMW}$ at all of the curing times. The porosity factor of the hardened cement pastes released with a curing time of up to 28 days. Excessive CMW of up to $25 \mathrm{wt} \%$ reduced the properties of OPC.

Sukor et al. [17] argued that growing concern on global warming directly related to $\mathrm{CO}_{2}$ emissions is steering the implementation of carbon capture and storage (CCS). With Malaysia having an estimated 37 trillion standard cubic feet (Tscfd) of natural gas remains undeveloped in $\mathrm{CO}_{2}$ containing natural gas fields, there is a need to assess the viability of CCS implementation. This study performs a techno-economic analysis for CCS at an offshore natural gas field in Malaysia. The framework includes a gas field model, revenue model, and cost model. A techno-economic spreadsheet consisting of net present value (NPV), payback period (PBP), and internal rate of return (IRR) is developed over the gas field's production life of 15 years for four distinctive $\mathrm{CO}_{2}$ capture technologies, which are membrane, chemical absorption, physical absorption, and cryogenics. Results predict that physical absorption solvent (Selexol) as $\mathrm{CO}_{2}$ capture technology is most feasible with IRR of $15 \%$ and PBP of 7.94 years. The output from the techno-economic model and associated risks of the CCS project are quantified by employing sensitivity analysis, which indicated that the project NPV is exceptionally sensitive to gas price. On this basis, the economic performance of the project is reliant on revenues from gas sales, which is dictated by gas market price uncertainties.

Ahmed et al. [18] reported that a new type of silica hybrid material functionalized with Schiff base-propyl-thiol and propyl-thiol groups (adsorbents 1 and 2, respectively) was synthesized using a co-condensation method. The synthesized materials and their starting materials were successfully characterized using a variety of techniques such as Fourier transform infrared spectroscopy (FTIR), scanning electron microscopy, X-ray diffraction, nitrogen adsorption-desorption isotherms, the Brunauer-Emmett-Teller surface area calculation method, the Barrett, Joyner, and Halenda pore size calculation method, thermogravimetry analysis, and $1 \mathrm{H}$ and $13 \mathrm{C}$ nuclear magnetic resonance spectra. The results indicate that the new material (adsorbent 1 ) has a large surface and possesses different functional groups $(-\mathrm{SH},-\mathrm{OH},-\mathrm{C}=\mathrm{O}$ and $-\mathrm{N}=\mathrm{C})$. The newly synthesized hybrid materials (1 and 2) were investigated as potential adsorbents for removal of toxic heavy metals, such as $\mathrm{Pb}$ (II) from aqueous solutions. The adsorption results show that materials 1 and 2 have different sorption properties and were found to be effective adsorbents for $\mathrm{Pb}$ (II) removal from aqueous solutions. In addition, compound 1 exhibited a higher adsorption capacity for $\mathrm{Pb}$ (II) compared to compound 2. The results showed that the optimal $\mathrm{pH}$ for $\mathrm{Pb}$ (II) sorption was 6.5. Contact time was observed to occur after $30 \mathrm{~min}$ for $25 \mathrm{mg} / \mathrm{L} \mathrm{Pb}$ (II) concentration and adsorbent dose of $0.4 \mathrm{~g} / \mathrm{L}$ at $25^{\circ} \mathrm{C}$.

In the work of Revollar et al. [19], a comprehensive analysis of the environmental impact of the operation of a wastewater treatment plant (WWTP) using different control strategies is carried out considering the dynamic evolution of some environmental indicators and average operation costs. The selected strategies are proportional integral (PI) control schemes such as dissolved oxygen control in the aerobic zone (DO control), DO con- 
trol and nitrates control in the anoxic zone (DO + NO control) and regulation of ammonium control at the end of aerobic zone (Cascade $S_{\text {NHSP }}$ ) commonly used in WWTPs to maintain the conditions that ensure the desired effluent quality in a variable influent scenario. The main novelty of the work is the integration of potential insights into environmental impact from the analysis of dynamic evolution of environmental indicators at different time scales. The consideration of annual, bimonthly and weekly temporal windows to evaluate performance indicators makes it possible to capture seasonal effects of influent disturbances and control actions on the environmental costs of wastewater treatment that are unnoticed in the annual-based performance evaluation. Then, in the case of periodic events, it is possible to find solutions to improve operation by the adjustment of the control variables in specific periods of time along the operation horizon. The analysis of the annual average and dynamic profiles (weekly and bimonthly) of environmental indicators showed that ammonium-based control (Cascade $\mathrm{S}_{\mathrm{NHSP}}$ ) produce the best compromise solution between environmental and operation costs compared with DO control and DO + NO control. An alternative control strategy, named $S_{\text {NHSP var }} Q_{\text {carb var, }}$, has been defined considering a sequence of changes on ammonium set-point $\left(\mathrm{S}_{\mathrm{NHSP}}\right)$ and carbon dosage $\left(\mathrm{Q}_{\text {carb }}\right)$ on different temporal windows. It is compared with DO control considering weekly and bimonthly profiles and annual average values leading to the conclusion that both strategies, Cascade $\mathrm{S}_{\mathrm{NHSP}}$ and $\mathrm{S}_{\mathrm{NHSP} \text { var }} \mathrm{Q}_{\mathrm{carb} \text { var, }}$ produce an improvement of dynamic and annual average environmental performance and operation costs, but the benefits of Cascade $\mathrm{S}_{\mathrm{NHSP}}$ strategy are associated with reduction of electricity consumption and emissions to water, while the $S_{\text {NHSP var }} Q_{\text {carb var }}$ strategy reduces electricity consumption, use of chemicals (reducing external carbon dosage) and operation costs.

Zhang et al. [20] showed that magnesium silicate hydrate (M-S-H) cement, formed by reacting $\mathrm{MgO}, \mathrm{SiO}_{2}$, and $\mathrm{H}_{2} \mathrm{O}$, was used to encapsulate strontium radionuclide. Samples were prepared using light-burned magnesium oxide and silica fume, with sodium hexametaphosphate added to the mix water as a dispersant. The performance of the materials formed was evaluated by leach testing and the microstructure of the samples was also characterized. The stabilising/solidifying effect on Sr radionuclide in the $\mathrm{MgO}-\mathrm{SiO}_{2}-\mathrm{H}_{2} \mathrm{O}$ system with low alkalinity was demonstrated in the study. The leaching rate in a standard 42-day test was $2.53 \times 10^{-4} \mathrm{~cm} / \mathrm{d}$, and the cumulative 42 -day leaching fraction was $0.06 \mathrm{~cm}$. This meets the relevant national standard performance for leaching requirements. $\mathrm{Sr}^{2+}$ was effectively incorporated into the M-S-H hydration products and new phase formation resulted in low Sr leaching being observed.

Nekouei et al. [21] studied the unprecedented advances and innovation in technology and short lifespans of electronic devices for the generation of a considerable amount of electronic waste (e-waste). Polymeric components present in electronic waste contain a wide range of organic materials encompassing a significant portion of carbon $(\mathrm{C})$. This source of carbon can be employed as a reducing agent in the reduction of oxides from another waste stream, i.e., steelmaking slag, which contains $20-40 \mathrm{wt} \%$ iron oxide. This waste slag is produced on a very large scale by the steel industry due to the nature of the process. In this research, the polymeric residue leftover from waste printed circuit boards after a physical-chemical recycling process was used as the source of carbon in the reduction of iron oxide from electric arc furnace slag. Prior to the recycling tests, the polymer content of e-waste was characterized in terms of composition, morphology, thermal behaviour, molecular structure, hazardous elements such as $\mathrm{Br}$, the volatile portion, and the fixed carbon content. After the optimisation of the ratio between the waste slag (Fe source) and the waste polymer (the carbon source), the microstructure of the recycled alloy showed no $\mathrm{Br}, \mathrm{Cl}, \mathrm{S}$, or other contamination. Hence, two problematic and complex waste streams were successfully converted to a clean alloy with $4 \mathrm{wt} \% \mathrm{C}, 4 \% \mathrm{Cr}, 2 \% \mathrm{Si}, 1 \% \mathrm{Mn}$, and $89 \% \mathrm{Fe}$.

Zhou et al. [22] evaluated the direct release to the environment of a number of potentially toxic elements (PTEs) from various processing nodes at Xikuangshan Antimony Mine in Hunan Province, China. Sampling wastewater, processing dust, and solid waste 
and characterising PTE content (major elements $\mathrm{Sb}, \mathrm{As}, \mathrm{Zn}$, and associated $\mathrm{Hg}, \mathrm{Pb}$, and Cd) from processing activities, we extrapolated findings to assess wider environmental significance using the pollution index and the potential ecological risk index. The Sb, As, and $\mathrm{Zn}$ in wastewater from the antimony benefication industry and a wider group of PTEs in the fine ore bin were significantly higher than their reference values. The content of $\mathrm{Sb}$, As, and $\mathrm{Zn}$ in tailings were relatively high, with the average value being 2674, 1040, and $590 \mathrm{mg} \cdot \mathrm{kg}^{-1}$, respectively. The content of PTEs in the surface soils surrounding the tailings was similar to that in tailings, and much higher than the background values. The results of the pollution index evaluation of the degree of pollution by PTEs showed that while dominated by $\mathrm{Sb}$, some variation in order of significance was seen namely for: (1) The ore processing wastewater $\mathrm{Sb}>\mathrm{Pb}>\mathrm{As}>\mathrm{Zn}>\mathrm{Hg}>\mathrm{Cd}$, (2) in dust $\mathrm{Sb}>\mathrm{As}>\mathrm{Cd}>$ $\mathrm{Pb}>\mathrm{Hg}>\mathrm{Zn}$, and (3) surface soil (near tailings) $\mathrm{Sb}>\mathrm{Hg}>\mathrm{Cd}>\mathrm{As}>\mathrm{Zn}>\mathrm{Pb}$. From the assessment of the potential ecological risk index, the levels were most significant at the three dust generation nodes and in the soil surrounding the tailings reservoir.

Omer et al. [23] reported that high energy demand has led to excessive fuel consumption and high-concentration $\mathrm{CO}_{2}$ production. $\mathrm{CO}_{2}$ release causes serious environmental problems such as the rise in the Earth's temperature, leading to global warming. Thus, chemical industries are under severe pressure to provide a solution to the problems associated with fuel consumption and to reduce $\mathrm{CO}_{2}$ emission at the source. To this effect, herein, four highly porous aromatic Schiff bases derived from melamine were investigated as potential media for $\mathrm{CO}_{2}$ capture. Since these Schiff bases are highly aromatic, porous, and have a high content of heteroatoms (nitrogen and oxygen), they can serve as $\mathrm{CO}_{2}$ storage media. The surface morphology of the Schiff bases was investigated through field emission scanning electron microscopy, and their physical properties were determined by gas adsorption experiments. The Schiff bases had a pore volume of $0.005-0.036 \mathrm{~cm}^{3} / \mathrm{g}$, an average pore diameter of 1.69-3.363 nm, and a small Brunauer-Emmett-Teller surface area $\left(5.2-11.6 \mathrm{~m}^{2} / \mathrm{g}\right.$ ). The Schiff bases showed remarkable $\mathrm{CO}_{2}$ uptake (up to $2.33 \mathrm{mmol} / \mathrm{g}$; $10 \mathrm{wt} \%$ ) at $323 \mathrm{~K}$ and 40 bars. The Schiff base containing the 4-nitrophenyl substituent was the most efficient medium for $\mathrm{CO}_{2}$ adsorption and, therefore, can be used as a gas sorbent.

In the study of Pinto et al. [24], post combustion $\mathrm{CO}_{2}$ capture is still a rather energy intense, and therefore expensive, process. Much of the current research for reducing the process energy requirements is focused on the regeneration section. A good description of the vapour-liquid equilibrium of the solvent is necessary for the accurate representation of the process. 3-(Diethylamino)-1,2-propanediol (DEA-12-PD) and 1-(2-hydroxyethyl)piperidine (12-HEPP) were proposed as potential components in solvent blends for the membrane contactor. However, there are few available experimental data for these two tertiary amines making it difficult to accurately simulate such process. In this work, we provide experimental data on the pure component saturation pressure ( 383 to $443 \mathrm{~K}$ ) and on VLE of aqueous solutions of these amines ( 313 to $373 \mathrm{~K}$ ) in order to fill part of the data gap. The data were used to estimate model parameters used to represent the data. The saturation pressure was modeled using the Antoine equation and the deviation was calculated as lower than $2 \%$. The NRTL model was used in this work to calculate the activity coefficients in the aqueous systems. The deviations in pressure for the aqueous systems were lower than $5 \%$ in both systems.

Nicolaou et al. [25] studied the $\mathrm{Cu}$ (II) adsorption from aqueous solutions by magnetic biochar obtained from pine needles by means of batch-type experiments. The biochar fibers were magnetized prior (pncm: carbonized-magnetized pine needles) and after oxidation (pncom: carbonized-oxidized-magnetized pine needles) and were used as adsorbents to study the presence of carboxylic moieties on the magnetisation and following adsorption process. The effect of $\mathrm{pH}(2-10)$, initial metal concentration $\left(10^{-5}-9 \times 10^{-3} \mathrm{~mol} / \mathrm{L}\right)$ and contact time (0-60 min) was studied by varying the respective parameter, and the adsorbents have been characterized by FTIR and XRD measurements prior and after $\mathrm{Cu}(\mathrm{II})$-adsorption. FTIR measurements were performed to investigate the formation of surface species and XRD measurements to record possible solid phase formation and characterize formed 
solids, including the evaluation of their average crystal size. The data obtained from the batch-type studies show that the oxidized magnetic biochar (pncom) presented significantly higher adsorption capacity $(1 \mathrm{mmol} / \mathrm{g})$ compared to pncm $(0.4 \mathrm{mmol} / \mathrm{g})$, which was ascribed to the synergistic effect of the carboxylic moieties present on the pncom surface, and the adsorption process follows the pseudo-second order kinetics. On the other hand, the FTIR spectra proved the formation of inner-sphere complexes and XRD diffractograms indicated $\mathrm{Cu}(\mathrm{II})$ solid phase formation at $\mathrm{pH} 6$ and increased metal ion concentrations.

Meng et al. [26] studied the filtration performances of different polysaccharides in microfiltration process. Membrane technology has been widely applied for water treatment, while membrane fouling still remains a big challenge. The polysaccharides in extracellular polymeric substances (EPS) have been known as a significant type of foulant due to their high fouling propensity. However, polysaccharides have many varieties which definitely behave differently in membrane filtration. Therefore, in this study, different polysaccharides, alginate sodium and xanthan gum, were chosen to study their effects on membrane fouling in a wide concentration range. The results demonstrated that the filtration behaviours of alginate sodium and xanthan gum were completely different, which was due to their different molecular structures. Alginate had a small molecular weight and it was easy for alginate to penetrate membrane pores resulting in pore blocking. A series of concentrations of alginate including $5 \mathrm{mg} / \mathrm{L}, 10 \mathrm{mg} / \mathrm{L}, 20 \mathrm{mg} / \mathrm{L}, 30 \mathrm{mg} / \mathrm{L}, 40 \mathrm{mg} / \mathrm{L}$, and $50 \mathrm{mg} / \mathrm{L}$ were examined and it was found that the permeate flux decline highly depended on the level of alginate in the feed water. For the filtration of xanthan gum, the same concentration of xanthan gum led to more serious fouling than that observed in alginate, which might be due to its large molecule. In addition, calcium chloride was added in the solutions of both alginate and xanthan gum to examine the influence of a divalent cation on polysaccharide fouling. A "unimodal" peak can be observed in the fouling propensity caused by $\mathrm{Ca}^{2+}$ and alginate by increasing the concentration of alginate. Such a phenomenon was not found in the fouling of xanthan gum and $\mathrm{Ca}^{2+}$ led to more serious fouling for all concentrations of xanthan gum. In light of this, this study gave new insights into the fouling propensities of different polysaccharides.

The traditional treatment of waste incineration flue gas is mostly carried out in low temperatures, but there are some problems such as corrosion of the heating surface at high and low temperatures, re-synthesis of dioxins, and low efficiency. Therefore, it is necessary to remove the pollutants at high temperatures. For the grate waste incinerator, Chen et al. [27] proposes an adiabatic cyclone flue arranged at the exit of the first-stage furnace of the grate waste incinerator to pre-remove the fly ash at high temperatures, so as to alleviate the abrasion and corrosion of the tail heating surface. In this paper, the computational fluid dynamics (CFD) method is applied to study the performance of a cyclone flue under different structural parameters, and the comprehensive performance of the cyclone flue is evaluated by the technique for order preference by similarity to an ideal solution method. The results show that particle separation efficiency increases at first and then decreases with the increase of the vortex finder length, the vortex finder diameter, and the distance between vortex finder and gas outlet tube, while it decreases with the increase of the gas outlet tube diameter. The pressure drop increases with the increase of the vortex finder length, and the vortex finder diameter, while it decreases with the increase of the distance between the vortex finder, the gas outlet tube, and the gas outlet tube diameter. In the scope of this study, when $h_{1} / a=1.1, D_{1} / A=0.33, h_{2} / A=1.5$, and $D_{2} / A=0.50$, the comprehensive performance of the cyclone flue is much better.

In the study of Meng et al. [28], the filtration behaviours of alginate blocks derived from the same source were comprehensively explored. Alginate blocks share the same chemical composition but differ from each other in molecular structure. The alginate was first extracted from natural seaweed using calcium precipitation and ion-exchange methods. Extracted alginate was further fractionised into MG-, MM- and GG-blocks and the characteristics of the three blocks were examined by Fourier transform infrared spectroscopy and field emission scanning electron microscopy observations, and transparent exopolymer par- 
ticles' (TEPs) measurements. Results showed that MG-, MM- and GG-blocks had the same functional groups, but they showed different intermolecular interactions. TEP formation from MG-, MM- and GG-blocks revealed that the molecule crosslinking of them decreased in the order of MM-blocks > GG-blocks > MG-blocks. It was further found from microfiltration tests that these alginate blocks had completely different fouling propensities which can be explained by the TEP formation. TEPs would accumulate on membrane surfaces and worked as a pre-filter to avoid serious pore blocking of membrane. That all suggested that the membrane fouling was closely related to the molecular structure of foulant. It is expected that this study can provide useful insights into the fouling propensities of different types of polysaccharides during filtration processes.

Ariyanto et al. [29] examined change in pore structure and microstructure of nanoporous carbon after surface oxidation and how it affects the adsorption performance of metronidazole antibiotics. The surface oxidation was performed by hydrogen peroxide at $60{ }^{\circ} \mathrm{C}$. The properties of porous carbon were investigated by $\mathrm{N}_{2}$-sorption analysis (pore structure), scanning electron microscopy (surface morphology), the Boehm titration method (quantification of surface functional group), and Fourier transform infrared spectroscopy (type of surface functional group). The results showed that the oxidation of porous carbon by hydrogen peroxide has a minor defect in the carbon pore structure. Only a slight decrease in specific surface area $(8 \%)$ from its original value $\left(973 \mathrm{~m}^{2} / \mathrm{g}\right)$ was seen but more mesoporosity was introduced. The oxidation of porous carbon with hydrogen peroxide modified the amount of oxide groups i.e., phenol, carboxylic acid and lactone. Moreover, in the application the oxidised carbon exhibited a higher metronidazole uptake capacity of up to three-times manifold with respect to the pristine carbon.

Zhong et al. [30] reported that carbon emissions are inevitably linked to lifestyle and consumption behaviours, and the concept of "carbon footprinting" is now wellrecognised beyond academia. Life-cycle assessment (LCA) is one of the primary tools for assessing carbon footprints. The aim of this paper is to present a systematic review of literatures focusing on carbon footprint calculated with life-cycle assessment. We used CiteSpace software to draw the knowledge map of related research to identify and trace the knowledge base and frontier terminology. It was found that the LCA application in respect of carbon footprint studies was completed mainly for the following aspect: beef production and dairy industry, seafood and fishery, nutrition, urban structure and energy use. The CiteSpace analysis showed the development path of the above aspects, for example, beef production and the dairy industry, has been a long-term topic in this kind of research, while the topic of nutrition appeared in recent years. There was also a cluster of literature discussing footprint evaluation tools, such as comparing LCA with input-output analysis. The CiteSpace analysis indicated that earlier methodological literature still plays an important role in recent research. Moreover, through the analysis of burst keywords, it was found that agriculture productions (dairy, meat, fish, crop) as well as global climate issues (greenhouse gases emission, global warming potential) have always been areas of concern, which matches the result of co-citation analysis. Building materials (low-carbon building, natural buildings, sustainable buildings) and soil issues (soil carbon sequestration, soil organic carbon) are the topics of recent concern, which could arouse the attention of follow-up research.

The large amount of boron-bearing iron tailings in China is a resource for metals that needs to be more completely and efficiently utilised. In the evaluation of Lv et al. [31], the ammonium sulfate roasting process was used to make a controllable phase transformation to facilitate the subsequent extraction of valuable metals from boron-bearing iron tailings. The effects of roasting temperature, roasting time, the molar ratio of ammonium sulfate to tailings, and the particle size on the extraction of elements were investigated. The orthogonal experimental design of experiments was used to determine the optimal processing conditions. XRD, scanning electron microscope, and a simultaneous DSC-TG analyzer were used to assist in elucidating the mechanism of ammonium sulfate roasting. The experimental results showed that nearly all Fe, Al, and $\mathrm{Mg}$ were extracted under the 
following conditions: (1) the molar ratio of ammonium sulfate to iron tailings was $3: 1$; (2) the roasting temperature was $450^{\circ} \mathrm{C}$; (3) the roasting time was $120 \mathrm{~min} . ;$ and, (4) the particle size was less than $80 \mu \mathrm{m}$. The kinetics analysis indicated that the sulfation of metals was controlled by internal diffusion, with the apparent activation energies of $17.10 \mathrm{~kJ} / \mathrm{mol}$, $17.85 \mathrm{~kJ} / \mathrm{mol}, 19.79 \mathrm{~kJ} / \mathrm{mol}$, and $29.71 \mathrm{~kJ} / \mathrm{mol}$ for $\mathrm{Fe}, \mathrm{Al}, \mathrm{Mg}$, and $\mathrm{B}$, respectively.

Nhubu et al. [32] presented that six municipal solid waste management (MSWM) options (A1-A6) in Harare were developed and analyzed for their global warming, acidification, eutrophication and human health impact potentials using life-cycle assessment methodology to determine the least impactful option in Harare. Study findings will aid the development of future MSWM systems in Harare. A1 and A2 considered the landfilling and incineration, respectively, of indiscriminately collected MSW with energy recovery and byproduct treatment. Source-separated biodegradables were anaerobically treated with the remaining non-biodegradable fraction being incinerated in $\mathrm{A} 3$ and landfilled in A4. A5 and A6 had the same processes as in A3 and A4, respectively, except the inclusion of the recovery of $20 \%$ of the recoverable materials. The life-cycle stages considered were collection and transportation, materials recovery, anaerobic digestion, landfilling and incineration. A5 emerged as the best option. Materials recovery contributed to impact potential reductions across the four impact categories. Sensitivity analysis revealed that doubling materials recovery and increasing it to $28 \%$ under A5 resulted in zero eutrophication and acidification, respectively. Increasing material recovery to $24 \%$ and $26 \%$ under A6 led to zero acidification and eutrophication, respectively. Zero global warming and human health impacts under $\mathrm{A} 6$ were realised at $6 \%$ and $9 \%$ materials recovery levels, respectively.

In the investigation of Quintáns-Fondo et al. [33], chromium (as $\mathrm{Cr}(\mathrm{VI})$ ) and fluoride $\left(\mathrm{F}^{-}\right)$were frequently found in effluents from different industrial activities. In cases where these effluents reach soil, it can play an important role in retaining those pollutants. Similarly, different byproducts could act as bio-adsorbents to directly treat polluted waters or to enhance the purging potential of soil. This work used batch-type experiments to study competitive $\mathrm{Cr}(\mathrm{VI})$ and $\mathrm{F}^{-}$adsorption in two different soils and several kinds of byproducts. Both soils, as well as mussel shell, oak ash, and hemp waste showed higher adsorption for $\mathrm{F}^{-}$, while pyritic material, pine bark, and sawdust had a higher affinity for $\mathrm{Cr}(\mathrm{VI})$. Considering the binary competitive system, a clear competition between both elements in anionic form was shown, with decreases in adsorption of up to $90 \%$ for $\mathrm{Cr}(\mathrm{VI})$, and of up to $30 \%$ for $\mathrm{F}^{-}$. Adsorption results showed better fitting to Freundlich's than to Langmuir's model. None of the individual soils or byproducts were able to adsorb high percentages of both pollutants simultaneously, but this could be improved greatly by adding pine bark to increase $\mathrm{Cr}(\mathrm{VI})$ adsorption in soils, thus drastically reducing the risks of pollution and deleterious effects on the environment and on public health.

Agriculture has long been considered a great source of nitrogen $(\mathrm{N})$ to surface waters and a major cause of eutrophication. Thus, management practices at the farm-scale have since attempted to mitigate the $\mathrm{N}$ losses, although often limited in tile-drained agricultural catchments, which speed up the $\mathrm{N}$ transport, while minimising natural removal in the landscape. In the review paper of Mendes et al. [34], surface-flow constructed wetlands (SFWs) were implemented as an edge-of-field strategy to intercept tile drains and reduce the $\mathrm{N}$ loads by re-establishing ecosystems services of previously drained water ponded areas. These systems collect the incoming water volumes in basins sufficiently large to prolong the hydraulic residence time to a degree where biogeochemical processes between the water, soil, sediments, plants, macro and microorganisms can mediate the removal of $\mathrm{N}$. Despite their documented suitability, great intra and inter-variability in N treatment was still observed to date. Therefore, it is essential to thoroughly investigate the driving factors behind performance of SFWs, in order to support their successful implementation according to local catchment characteristics, and ensure compliance with $\mathrm{N}$ removal goals. This review contextualised the aforementioned issue, and critically evaluated the influence of hydrochemistry, hydrology and biogeochemistry in the treatment of N by SFWs. 
In the review paper of Tahoon et al. [35], the discharge of toxic heavy metals including zinc $(\mathrm{Zn})$, nickel $(\mathrm{Ni})$, lead $(\mathrm{Pb})$, copper $(\mathrm{Cu})$, chromium $(\mathrm{Cr})$, and cadmium $(\mathrm{Cd})$ in water above the permissible limits caused high threat to the surrounding environment. Because of their toxicity, heavy metals greatly affect the human health and the environment. Recently, better remediation techniques have been offered using the nanotechnology and nanomaterials. Attention was directed toward cost-effective and new fabricated nanomaterials for the application in water/wastewater remediation, such as zeolite, carbonaceous, polymer based, chitosan, ferrite, magnetic, metal oxide, bimetallic, metallic, etc. This review focused on the synthesis and capacity of various nanoadsorbent materials for the elimination of different toxic ions, with discussion of the effect of their functionalisation on the adsorption capacity and separation process. Additionally, the effect of various experimental physicochemical factors on heavy metals adsorption, such as ionic strength, initial ion concentration, temperature, contact time, adsorbent dose, and $\mathrm{pH}$ was discussed.

In the study of Pichardo-Romero et al. [36], membranes, as the primary tool in membrane separation techniques, tend to suffer external deposition of pollutants and microorganisms depending on the nature of the treating solutions. Such issues are well recognised as biofouling and identified as the major drawback of pressure-driven membrane processes due to the influence of the separation performance of such membrane-based technologies. Herein, the aim of this review paper was to elucidate and discuss new insights on the ongoing development works at facing the biofouling phenomenon in membranes. This work also provides an overview of the main strategies proposed by "membranologists" to improve the fouling resistance in membranes. Special attention was paid to the fundamentals on membrane fouling as well as the relevant results in the framework of mitigating the issue. By analyzing the literature data and state-of-the-art, the concluding remarks and future trends in the field are given as well.

At the end of this editorial, the editors would like to thank the authors and reviewers for their valuable contributions to this special issue and the editorial staff of Processes for their help and support during the review process.

Funding: This research received no external funding.

Conflicts of Interest: The authors declare no conflict of interest.

\section{References}

1. Pan, Z.; Zhang, N.; Zhang, W.; Zhang, Z. Simultaneous Removal of $\mathrm{CO}_{2}$ and $\mathrm{H}_{2} \mathrm{~S}$ from Coalbed Methane in a Membrane Contactor. J. Clean. Prod. 2020, 273, 123107. [CrossRef]

2. Wang, S.; Wu, Y. Hyperthermophilic Composting Technology for Organic Solid Waste Treatment: Recent Research Advances and Trends. Processes 2021, 9, 675. [CrossRef]

3. Cela-Dablanca, R.; Conde-Cid, M.; Ferreira-Coelho, G.; Arias-Estévez, M.; Fernández-Calviño, D.; Núñez-Delgado, A.; FernándezSanjurjo, M.J.; Álvarez-Rodríguez, E. Adsorption of Tetracycline and Sulfadiazine onto Three Different Bioadsorbents in Binary Competitive Systems. Processes 2020, 9, 28. [CrossRef]

4. Baena-Moreno, F.M.; Rodríguez-Galán, M.; Navarrete, B.; Vilches, L.F. Novel Study for Energy Recovery from the CoolingSolidification Stage of Synthetic Slag Manufacturing: Estimation of the Potential Energy Recovery. Processes 2020, 8, 1590. [CrossRef]

5. Do, T.H.; Nguyen, V.T.; Nguyen, Q.D.; Chu, M.N.; Ngo, T.C.Q.; Van Tan, L. Equilibrium, Kinetic and Thermodynamic Studies for Sorption of Phosphate from Aqueous Solutions Using ZnO Nanoparticles. Processes 2020, 8, 1397. [CrossRef]

6. Liu, L.; Jiao, Q.; Yang, J.; Kong, B.; Ren, S.; Liu, Q. Influences of Ash-Existing Environments and Coal Structures on $\mathrm{CO}_{2}$ Gasification Characteristics of Tri-High Coal. Processes 2020, 8, 1367. [CrossRef]

7. Siddiqi, M.M.; Naseer, M.N.; Wahab, Y.A.; Hamizi, N.A.; Badruddin, I.A.; Hasan, M.A.; Chowdhury, Z.Z.; Akbarzadeh, O.; Johan, M.R.; Kamangar, S. Exploring E-Waste Resources Recovery in Household Solid Waste Recycling. Processes 2020, 8, 1047. [CrossRef]

8. Ji, G.; Raheem, A.; Wang, X.; Fu, W.; Qu, B.; Gao, Y.; Li, A.; Zhao, M.; Dong, W.; Zhang, Z. Kinetic Analysis of Algae Gasification by Distributed Activation Energy Model. Processes 2020, 8, 927. [CrossRef]

9. Peceño, B.; Leiva, C.; Alonso-Fariñas, B.; Gallego-Schmid, A. Is Recycling Always the Best Option? Environmental Assessment of Recycling of Seashell as Aggregates in Noise Barriers. Processes 2020, 8, 776. [CrossRef]

10. Nkosi, N.; Muzenda, E.; Mamvura, T.A.; Belaid, M.; Patel, B. The Development of a Waste Tyre Pyrolysis Production Plant Business Model for the Gauteng Region, South Africa. Processes 2020, 8, 766. [CrossRef] 
11. Shaaban, M.; Wu, Y.; Wu, L.; Hu, R.; Younas, A.; Nunez-Delgado, A.; Xu, P.; Sun, Z.; Lin, S.; Xu, X.; et al. The Effects of pH Change through Liming on Soil N2O Emissions. Processes 2020, 8, 702. [CrossRef]

12. Charis, G.; Danha, G.; Muzenda, E. Characterizations of Biomasses for Subsequent Thermochemical Conversion: A Comparative Study of Pine Sawdust and Acacia Tortilis. Processes 2020, 8, 546. [CrossRef]

13. Magzoub, M.I.; Ibrahim, M.H.; Nasser, M.S.; El-Naas, M.H.; Amani, M. Utilization of Steel-Making Dust in Drilling Fluids Formulations. Processes 2020, 8, 538. [CrossRef]

14. Alberdi, E.; Urrutia, L.; Goti, A.; Oyarbide-Zubillaga, A. Modeling the Municipal Waste Collection Using Genetic Algorithms. Processes 2020, 8, 513. [CrossRef]

15. Huang, S.; You, Z.; Jiang, Y.; Zhang, F.; Liu, K.; Liu, Y.; Chen, X.; Lv, Y. Fabrication of Ultrathin MoS2 Nanosheets and Application on Adsorption of Organic Pollutants and Heavy Metals. Processes 2020, 8, 504. [CrossRef]

16. Abdelatif, Y.; Gaber, A.-A.M.; Fouda, A.E.-A.S.; Alsoukarry, T. Evaluation of Calcium Oxide Nanoparticles from Industrial Waste on the Performance of Hardened Cement Pastes: Physicochemical Study. Processes 2020, 8, 401. [CrossRef]

17. Sukor, N.R.; Shamsuddin, A.H.; Mahlia, T.M.I.; Isa, F.M. Techno-Economic Analysis of CO2 Capture Technologies in Offshore Natural Gas Field: Implications to Carbon Capture and Storage in Malaysia. Processes 2020, 8, 350. [CrossRef]

18. Ahmed, M.O.; Shrpip, A.; Mansoor, M. Synthesis and Characterization of New Schiff Base/Thiol-Functionalized Mesoporous Silica: An Efficient Sorbent for the Removal of $\mathrm{Pb}(\mathrm{II})$ from Aqueous Solutions. Processes 2020, 8, 246. [CrossRef]

19. Revollar, S.; Meneses, M.; Vilanova, R.; Vega, P.; Francisco, M. Quantifying the Benefit of a Dynamic Performance Assessment of WWTP. Processes 2020, 8, 206. [CrossRef]

20. Zhang, T.; Zou, J.; Li, Y.; Jia, Y.; Cheeseman, C.R. Stabilization/Solidification of Strontium Using Magnesium Silicate Hydrate Cement. Processes 2020, 8, 163. [CrossRef]

21. Nekouei, R.K.; Maroufi, S.; Assefi, M.; Pahlevani, F.; Sahajwalla, V. Thermal Isolation of a Clean Alloy from Waste Slag and Polymeric Residue of Electronic Waste. Processes 2020, 8, 53. [CrossRef]

22. Zhou, S.; Deng, R.; Hursthouse, A. Risk Assessment of Potentially Toxic Elements Pollution from Mineral Processing Steps at Xikuangshan Antimony Plant, Hunan, China. Processes 2019, 8, 29. [CrossRef]

23. Omer, R.M.; Al-Tikrity, E.T.B.; El-Hiti, G.A.; Alotibi, M.F.; Ahmed, D.S.; Yousif, E. Porous Aromatic Melamine Schiff Bases as Highly Efficient Media for Carbon Dioxide Storage. Processes 2019, 8, 17. [CrossRef]

24. Pinto, D.D.D.; Zahraee, Z.; Buvik, V.; Hartono, A.; Knuutila, H.K. Vapor Liquid Equilibrium Measurements of Two Promising Tertiary Amines for CO2 Capture. Processes 2019, 7, 951. [CrossRef]

25. Nicolaou, E.; Philippou, K.; Anastopoulos, I.; Pashalidis, I. Copper Adsorption by Magnetized Pine-Needle Biochar. Processes 2019, 7, 903. [CrossRef]

26. Meng, S.; Liu, H.; Zhao, Q.; Shen, N.; Zhang, M. Filtration Performances of Different Polysaccharides in Microfiltration Process. Processes 2019, 7, 897. [CrossRef]

27. Chen, D.-M.; Ran, J.-Y.; Niu, J.-T.; Yang, Z.-Q.; Pu, G.; Yang, L. Numerical Study on Separation Performance of Cyclone Flue Used in Grate Waste Incinerator. Processes 2019, 7, 866. [CrossRef]

28. Meng, S.; Wang, R.; Zhang, M.; Meng, X.; Liu, H.; Wang, L. Insights into the Fouling Propensities of Natural Derived Alginate Blocks during the Microfiltration Process. Processes 2019, 7, 858. [CrossRef]

29. Ariyanto, T.; Sarwendah, R.A.G.; Amimmal, Y.M.N.; Laksmana, W.T.; Prasetyo, I. Modifying Nanoporous Carbon through Hydrogen Peroxide Oxidation for Removal of Metronidazole Antibiotics from Simulated Wastewater. Processes $2019,7,835$. [CrossRef]

30. Zhong, S.; Chen, R.; Song, F.; Xu, Y. Knowledge Mapping of Carbon Footprint Research in a LCA Perspective: A Visual Analysis Using CiteSpace. Processes 2019, 7, 818. [CrossRef]

31. Lv, X.; Cui, F.; Ning, Z.; Free, M.L.; Zhai, Y. Mechanism and Kinetics of Ammonium Sulfate Roasting of Boron-Bearing Iron Tailings for Enhanced Metal Extraction. Processes 2019, 7, 812. [CrossRef]

32. Nhubu, T.; Muzenda, E. Determination of the Least Impactful Municipal Solid Waste Management Option in Harare, Zimbabwe. Processes 2019, 7, 785. [CrossRef]

33. Quintáns-Fondo, A.; Ferreira-Coelho, G.; Arias-Estévez, M.; Nóvoa-Muñoz, J.C.; Fernández-Calviño, D.; Álvarez-Rodríguez, E.; Fernández-Sanjurjo, M.J.; Núñez-Delgado, A. Chromium VI and Fluoride Competitive Adsorption on Different Soils and By-Products. Processes 2019, 7, 748. [CrossRef]

34. Mendes, L.R.D. Nitrogen Removal from Agricultural Subsurface Drainage by Surface-Flow Wetlands: Variability. Processes 2021, 9, 156. [CrossRef]

35. Tahoon, M.A.; Siddeeg, S.M.; Alsaiari, N.S.; Mnif, W.; Ben Rebah, F. Effective Heavy Metals Removal from Water Using Nanomaterials: A Review. Processes 2020, 8, 645. [CrossRef]

36. Pichardo-Romero, D.; Garcia-Arce, Z.P.; Zavala-Ramírez, A.; Castro-Muñoz, R. Current Advances in Biofouling Mitigation in Membranes for Water Treatment: An Overview. Processes 2020, 8, 182. [CrossRef] 